УДК 550.837.312:556.531.4

\title{
ГИДРОХИМИЧЕСКИЕ И ГАЗОВЫЕ АНОМАЛИИ НА СУЛЬФИДНОМ ХВОСТОХРАНИЛИЩЕ (САЛАИР, КЕМЕРОВСКАЯ ОБЛАСТЬ)
}

\author{
Бортникова Светлана Борисовна 1 , \\ BortnikovaSB@ipgg.sbras.ru
}

Юркевич Наталия Викторовна', YurkevichNV@ipgg.sbras.ru

Еделев Алексей Викторович ${ }^{\text {, }}$ EdelevAV@ipgg.sbras.ru

\author{
Грахова София Павловна 1 \\ GrakhovaSP@ipgg.sbras.ru
}

\author{
Волынкин Сергей Сергеевич 1 , \\ VolynkinSS@ipgg.sbras.ru
}

Карин Юрий Григорьевич 1 , KarinYG@ipgg.sbras.ru

\author{
Саева Ольга Петровна 1 , \\ SaevaOP@ipgg.sbras.ru \\ 1 Институт нефтегазовой геологии и геофизики им. А.А. Трофимука СО РАН, \\ Россия, 630090, г. Новосибирск, пр. Академика Коптюга, 3.
}

\begin{abstract}
Актуальность исследования связана с получением новых данных по процессам, происходящим в складированных сульффидных отходах, их трансформации под действием окислительных факторов, миграции токсичных компонентов в окружающую среду. Цель: определение вертикальной зональности по элементному составу и содержанию газов (сероуглерода и диметилсульфида) в хвостохранилище, а также установление гидрохимических аномалий в ближайшей реке в результате миграции потенциально токсичных элементов с водными потоками из отходов.

Объект: заброшенное хвостохранилище Салаирского горно-обогатительного комбината - Талмовские Пески (2. Салаир, Кемеровская область), вмещающее отходы цианирования и фрлотации барит-полиметаллических руд.

Методы. В полевых условиях проводилась термометрия, газовый анализ, электроразведка методом сопротивлений в режиме электротомографии. Отбор твердых и жидких проб выполнялся в соответствии с общепринятыми методиками. Лабораторное изучение химического состава проб проводилось методами кондуктометрии, потенциометрии, капиллярного электроффореза, масс-спектрометрии с индуктивно связанной плазмой.

Результаты. Распределение общих концентраций элементов по вертикали определяется неоднородностью складированного материала отходов. На примере двух разрезов до глубины 1,2 м определено, что влажность вещества возрастает с глубиной, а температура, значения $\mathrm{pH}$ паст и водных вытяжек снижаются. С глубиной закономерно возрастает количество водорастворимых форм металлов за счет преобразования сульфидов в кислых условиях, а также вследствие поступления из верхних горизонтов. Газогенерация сероуглерода и диметилсульфида, напротив, возрастает к верхним слоям хвостохранилища, что, всего скорее, связано как с их накоплением, так и интенсивным преобразованием минеральной матрицы и активным функционированием биоты в верхних прогреваемых слоях с нейтральной реакцией среды. В результате активных взаимодействий вещества отходов с водой и газами в реке Малой Талмовой, в русле которой расположено хвостохранилище, формируются контрастные гидрохимические аномалии с высокими кониентрациями металлов.
\end{abstract}

\section{Ключевые слова:}

Хвостохранилище, газовыделение, микроэлектротомография, серосодержащие газы, загрязнение природных вод, удельное электрическое сопротивление, кислье воды.

\section{Введение}

Проблема складированных сульфидных отходов, их трансформации под действием окислительных факторов, миграции токсичных компонентов в окружающую среду исследуется и обсуждается широко [1-6 и многие другие]. Разрушение сульфидных минералов приводит к растворению вещества, формированию кислых потоков с высокими концентрациями металлов и металлоидов $[7,8]$. На окружающих хранилища территориях образуются контрастные аномалии металлов и металлоидов в почвах [9-11], водоемах [12-14]. Кроме того, из сульфидсодержащих отходов выделяется целый спектр азот-, серо- и селенсодержащих газов, в том числе и неорганического происхождения, а также под воздействием микробиологических процессов, в том числе и метилирования [15-17]. В результате вещество отходов находится в постоянном взаимодействии со специфическим флюидом, состоящим из смеси жидкой и газовой фаз и характеризующимся широким диапазоном физикохимических параметров, концентраций макро- и микроэлементов в зависимости от условий формирования и состава вмещающей среды. Следствием взаимодействий в системе твердое-вода-газ в условиях сульфидных отходов являются водные и газовые потоки, распространяющиеся в окружающей среде. При этом на фоне широкого обсуждения различных закономерностей и особенностей кислого дренажа процессы газообразования в сульфидных отходах остаются малоизученными. Проведено комплексное исследование состава, строения и зональности, включая газообразование, одного из хвостохранилищ Западной Сибири, информация о котором представлена в статье [18].

Цели данной работы: 1) определение вертикальной зональности хвостохранилища, образованного 80-90 лет назад в русле реки Малая Талмовая (Гурьевский район, Кемеровская область); 2) выявление закономерностей концентрирования подвижных форм 
элементов по разрезу; 3) оценка уровня образования газов сероуглерода и диметилсульфида в разных горизонтах хвостохранилища; 4) установление гидрохимических аномалий в р. Малая Талмовая в результате миграции потенциально токсичных элементов с водными потоками из хвостохранилища.

\section{Объект исследования}

Хвостохранилище Талмовские Пески расположено в г. Салаир, в Кемеровской области (рис. 1).

Салаирский горно-обогатительный комбинат начал работать с 30-х гг. прошлого века и разрабатывал золото- и серебросодержащие баритполиметаллические руды месторождений Салаирского рудного поля, приуроченного к кембрийскому палеовулканическому куполу. Купол поднимается среди мощного комплекса известняков гавриловской свиты нижнекембрийского возраста $\left(€_{1} \mathrm{gv}\right)$. Сложен он порфирами риолит-дацитового состава, туфами, туффитами, андезитовыми порфиритами, дацитовыми порфирами. Рудные тела приурочены к нижнекембрийским субвулканическим кварц-плагиоклазовым порфирам печеркинской свиты ( $€_{1}$ рс $)$. Геологическое строение поля и минералогия рудных тел детально изучены и описаны многими сибирскими геологами [19-23]. Рудные тела месторождения представляют собой гидротермально-метасоматические образования сливных и прожилково-вкрапленных руд. Сульфиды представлены пиритом, халькопиритом, сфалеритом, галенитом, блеклыми рудами (теннантит). К редким минералам рудных тел, обнаруженных в кварц-карбонатных штокверках, пересекающих барит-полиметаллические тела, относятся сульфосоли (пирсеит, полибазит), теллуриды серебра, золота и свинца (гессит, петцит, эмпрессит, алтаит), самородное золото и серебро [24]. Жильные минералы: кварц, барит, кальцит, серицит и хлорит.
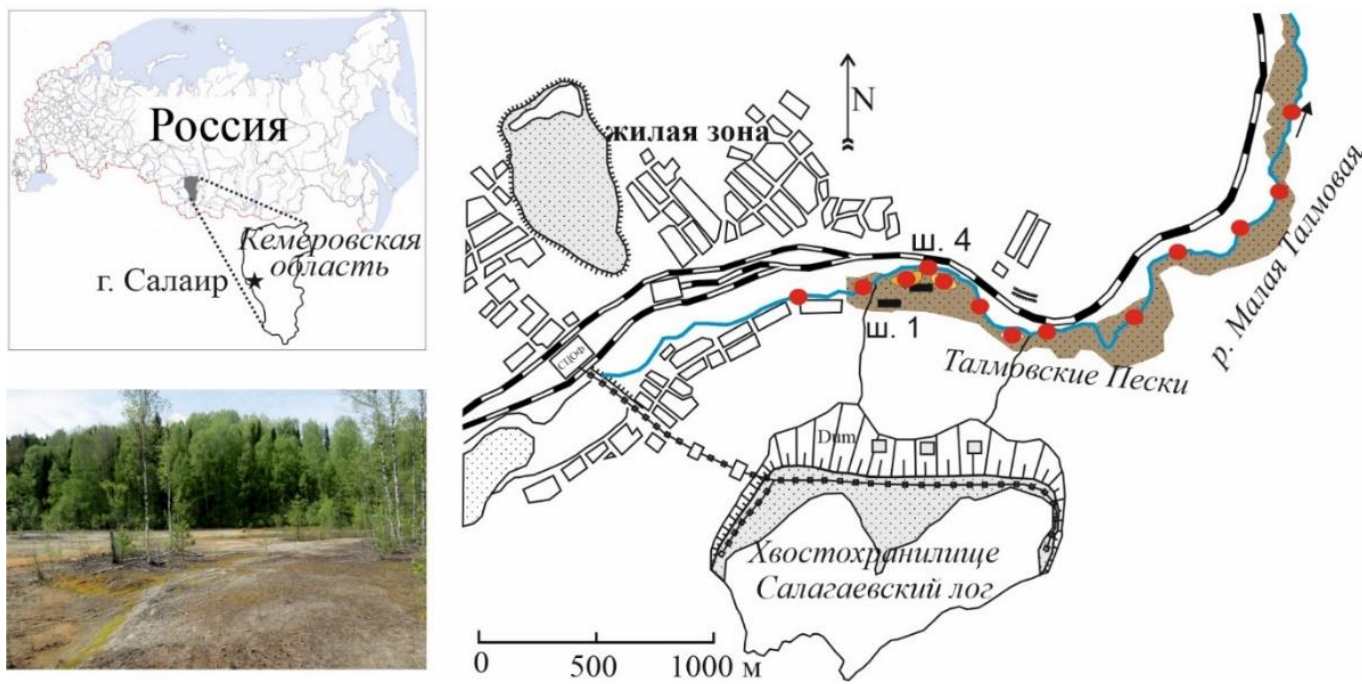

Рис. 1. Географическое положение, схема опробования и внешний вид хвостохранилища Талмовские Пески. Черные прямоугольники - участки шурфов (ш. 1 и 4); красные кружки - точки отбора проб воды по реке Малой Талмовой и в водоёмах

Fig. 1. Geographical location, sampling scheme and appearance of the Talmovskie Peski tailings dump. Black rectangles pits (pit 1 and 4); red circles - points of water sampling along the Malaya Talmovaya River and in water bodies

В начале эксплуатации месторождения разрабатывались верхние, наиболее богатые части рудных тел из зоны окисления. Переработка руд производилась на Золотоизвлекательной фабрике методами гравитации, цианирования и флотации.

С 1932 по 1942 гг. отходы обогащения складировались в запруженное дамбой русло реки Малой Талмовой. После заполнения отходами получившегося искусственного пруда ниже по течению сооружалась следующая дамба, и процесс повторялся. В настоящее время хвостохранилище Талмовские Пески представляет собой узкую (до 30 м) ленту песков протяженностью около 8 км, в непосредственной близости от которых протекает река Малая Талмовая. Мощность техногенных отложений не превышает 3 м, что составляет около 1 млн т. Вещество отходов подвержено интенсивному окислению за счет кислорода атмосферы и сезонных осадков, в результате чего суль- фидные минералы подвержены значительному разрушению и преобразованию [25].

\section{Методы. Полевые исследования}

Во время полевых работ были выкопаны несколько шурфов на хвостохранилище на всю глубину песков, до подстилающих почв. В данном случае почвы оказались уже на глубине 120 см. По стенкам шурфов описана зональность и опробованы все визуально различающиеся слои. Пробы отбирались титановым совком и упаковывались в герметично закрывающиеся пакеты (грипперы).

В каждом слое измерялись температура вещества электронным термометром ЛТ-300-Н (производство ООО «ТЕРМЭКС», г. Томск) и концентрации газов (сероуглерода и диметилсульфида) мобильным газоанализатором ГАНК-4М (производство ООО НПО «Прибор» ГАНК, г. Москва). В измеряемом участке 
стенки шурфа делалось небольшое углубление, в котором производилось измерение газов. Таким образом мы получали концентрацию газов в поровом пространстве.

По линии каждого шурфа были построены профили микроэлектротомографии для выявления геоэлектрической зональности и сопоставления её с геохимическими параметрами. Измерения проводились многоэлектродной установкой Скала-48, расстояние между электродами - 30 см, длина профиля - 14,1 м. Последовательность подключения электродов соответствовала симметричной установке Шлюмберже. Решение обратной задачи электроразведки выполнялось с помощью программы Res2Dinv [26], при этом применялся сглаженный способ инверсии. В результате двумерной инверсии строились модели геоэлектрических разрезов. Ошибка решения обратной задачи не превышала $2 \%$.

Река Малая Талмовая была опробована летом 2020 г. от точки, расположенной выше по течению от складированных отходов, и далее через 200-250 м были взяты пробы воды на всем протекании реки по г. Салаир. Кроме того, были взяты пробы из трех небольших водоёмов рыжего цвета, образованных на поверхности отходов за счет сезонных осадков. Пробы воды брались в пластиковые одноразовые контейнеры с предварительным трёхкратным ополаскиванием в точке взятия пробы. На месте измерялись значения $\mathrm{pH}$ (pH/T-метром HI 9025 C, HANNA Instruments, США) и электропроводности (УЭП) кондуктометром Cond 315 i (WTW, США), пробы разделялись на две части. Одна часть, предназначенная для элементного анализа, фильтровалась через мембранный фильтр
$0,45 \mu$ и затем подкислялась ультрачистой $\mathrm{HNO}_{3}$ до $\mathrm{pH}$ 2. Вторую часть оставляли нетронутой, для определения основных анионов. Затем контейнеры герметично закрывались и хранились в прохладном месте.

\section{Лабораторные анализы}

В лабораторных условиях пробы из шурфов были гомогенизированы и разделены на три части. В первой части была измерена влажность весовым методом, и затем сухие пробы были истерты для анализов. Из второй части были приготовлены пасты (твердое/вода=2/1) для определения кислотно-основного баланса вещества [27], и в них измерены значения $\mathrm{pH}$ и электропроводности вышеупомянутыми приборами. Водные вытяжки (твердое/вода=1/10) для определения концентраций подвижных форм элементов были приготовлены из третьей части проб. В водных вытяжках также были измерены значения рН и электропроводности. Концентрации основных ионов определялись методом капиллярного электрофореза на приборе «Капель 105-М» (Люмэкс, г. Санкт-Петербург). Микроэлементный состав определялся методом массспектрометрии с индуктивно связанной плазмой на приборе Agilent 8800 (Agilent Technologies, США).

\section{Результать}

В вертикальном строении хвостохранилища проявилась большая неоднородность, как в составе вещества, так и в физико-химических характеристиках. Общей для всех разрезов закономерностью является увеличение влажности вещества, кислотности среды, электропроводности (с некоторыми колебаниями) с глубиной (рис. 2)

\section{электропроводность пасты, мСм/см}
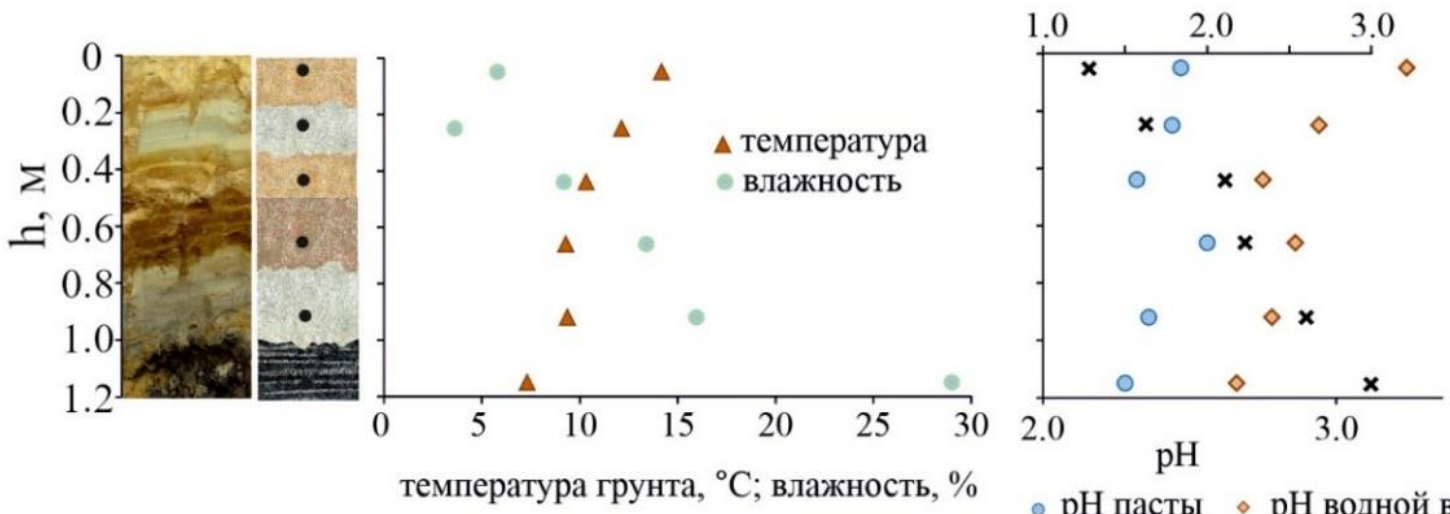

- $\mathrm{pH}$ пасты • $\mathrm{pH}$ водной вытяжки

× электропроводность

Pис. 2. Изменение параметров вещества хвостохранилища с глубиной (шурф № 1)

Fig. 2. Change in the parameters of the tailing dump matter with depth (pit no. 1)

Температура и концентрации газов закономерно снижаются к нижним горизонтам. Наибольшие концентрации газов обнаружены в верхних горизонтах, в то время как накопление растворимых форм элементов происходит в нижних частях разреза, причем вне зависимости от их валового содержания (рис. 3).
Окисление сульфидов, в первую очередь, пирита, ведет к образованию кислоты, выходу металлов в растворы и увеличению минерализации поровых вод согласно реакциям (1)-(4) [3], где обозначениями (s), (g), (l), (aq) обозначены твердая, газообразная, жидкая и растворенная формы вещества, соответственно. 


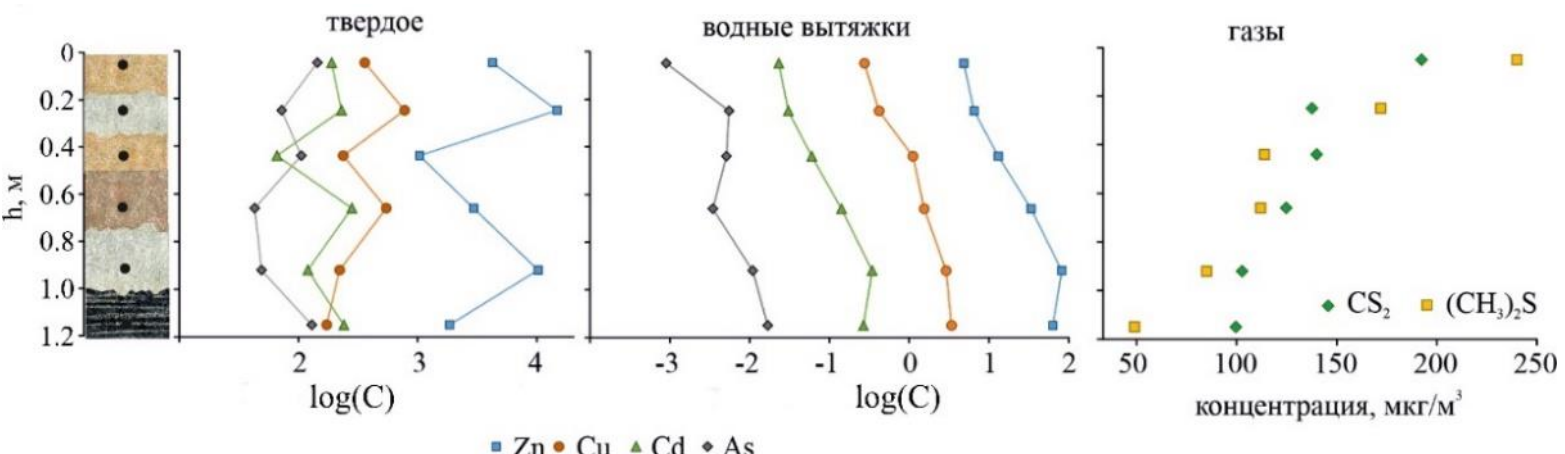

Рис. 3. Распределение общих концентраций металлов, их подвижных форм и некоторых газов по вертикали (иурф № 1). Примечание: $\log (C)$ - десятичный логарифм содержания элемента, выраженного в мг/л и в г/m в воде и в твердом веществе, соответственно

Fig. 3. Vertical distribution of total concentrations of metals, their mobile forms and some gases (pit no. 1). Note: $\log (C)$ is the decimal logarithm of the element content, expressed in $\mathrm{mg} / \mathrm{l}$ and $\mathrm{g} / \mathrm{t}$ in water and solid, respectively

$$
\begin{gathered}
\mathrm{FeS}_{2(\mathrm{~s})}+15 / 4 \mathrm{O}_{2(\mathrm{~g})}+7 / 2 \mathrm{H}_{2} \mathrm{O}_{(\mathrm{l})} \rightarrow \\
\rightarrow \mathrm{Fe}(\mathrm{OH})_{3(\mathrm{~s})}+2 \mathrm{SO}_{4}{ }^{2-}{ }_{(\mathrm{aq})}+4 \mathrm{H}^{+}{ }_{(\mathrm{aq})}, \\
\mathrm{CuFeS}{ }_{2(\mathrm{~s})}+17 / 4 \mathrm{O}_{2(\mathrm{~g})}+5 / 2 \mathrm{H}_{2} \mathrm{O}_{(\mathrm{l})} \rightarrow \\
\rightarrow \mathrm{Fe}(\mathrm{OH})_{3(\mathrm{~s})}+2 \mathrm{SO}_{4}{ }^{2-}{ }_{(\mathrm{aq})}+\mathrm{Cu}^{2}{ }_{(\mathrm{aq})}+2 \mathrm{H}^{+}{ }_{(\mathrm{aq})}, \\
(\mathrm{Zn}, \mathrm{Fe}) \mathrm{S}_{(\mathrm{s})}+\mathrm{O}_{2(\mathrm{~g})}+\mathrm{H}_{2} \mathrm{O}_{(\mathrm{l})} \rightarrow \\
\rightarrow \mathrm{Fe}(\mathrm{OH})_{3(\mathrm{~s})}+\mathrm{SO}_{4}{ }^{2-}{ }_{(\mathrm{aq})}+\mathrm{Zn}^{2+}{ }_{(\mathrm{aq})}+\mathrm{H}^{+}{ }_{(\mathrm{aq})}, \\
\mathrm{FeAsS}{ }_{(\mathrm{s})}+7 / 2 \mathrm{O}_{2(\mathrm{~g})}+4 \mathrm{H}_{2} \mathrm{O}_{(\mathrm{l})} \rightarrow \\
\rightarrow \mathrm{FeAsO}{ }_{4} \cdot 3 \mathrm{H}_{2} \mathrm{O}_{(\mathrm{s})}+\mathrm{SO}_{4}{ }^{2-}{ }_{(\mathrm{aq})}+2 \mathrm{H}^{+}{ }_{(\mathrm{aq})} .
\end{gathered}
$$

Фильтрация поверхностных вод способствует миграции поровых растворов книзу и накоплению растворенных форм элементов в нижних частях разреза.

Формирование обсуждаемых газов: сероуглерода и диметилсульфида, происходит по разным механизмам. Согласно экспериментальным исследованиям $[28,29]$, сероуглерод $\left(\mathrm{CS}_{2}\right)$ и карбонилсульфид $(\mathrm{COS})$ абиогенно генерируются при разложении сульфидных минералов (в основном пирита) в неравновесных условиях. При этом образование диметилсульфида $\left(\left(\mathrm{CH}_{3}\right)_{2} \mathrm{~S}\right)$ предположительно может являться результатом жизнедеятельности микроорганизмов, а метилсульфид $\left(\mathrm{CH}_{3} \mathrm{SH}\right)$ может иметь как биогенное, так и абиогенное происхождение. На основе результатов предшествующих исследований [30, 31] предполагается, что для системы $\mathrm{FeS} / \mathrm{FeS}_{2}$ следующие взаимодействия в восстановительной обстановке приводят к образованию серосодержащих газов на примере $\mathrm{CS}_{2}$ и COS:

$$
\begin{gathered}
3 \mathrm{FeS}+3 \mathrm{H}_{2} \mathrm{~S} \leftrightarrow 3 \mathrm{FeS}_{2}+3 \mathrm{H}_{2}, \\
\mathrm{FeS}+\mathrm{nH}_{2} \mathrm{O} \rightarrow \mathrm{FeO}\left(\mathrm{H}_{2} \mathrm{O}\right)_{\mathrm{n}-1}+\mathrm{H}_{2} \mathrm{~S} \\
\mathrm{CO}_{2}+\mathrm{H}_{2} \mathrm{~S}+3 \mathrm{H}_{2} \rightarrow \mathrm{CH}_{3} \mathrm{SH}+2 \mathrm{H}_{2} \mathrm{O} \\
\mathrm{COS}+3 \mathrm{H}_{2} \rightarrow \mathrm{CH}_{3} \mathrm{SH}+\mathrm{H}_{2} \mathrm{O} \\
\mathrm{CO}_{2}+\mathrm{H}_{2} \mathrm{~S} \rightarrow \mathrm{COS}+\mathrm{H}_{2} \mathrm{O} \\
2 \mathrm{CH}_{3} \mathrm{SH}+2 \mathrm{H}_{2} \mathrm{O} \rightarrow 2 \mathrm{COS}+6 \mathrm{H}_{2}, \\
2 \mathrm{COS} \rightarrow \mathrm{CS}_{2}+\mathrm{CO}_{2} .
\end{gathered}
$$

Стоит отметить, что непосредственно механизм данных реакций не до конца раскрыт и система $\mathrm{FeS} / \mathrm{FeS}_{2}$ (равновесия 5,6 ) является важным участником абиогенной продукции $\mathrm{CS}_{2}$ и $\mathrm{COS}$, что подтверждается снижением количества генерируемых газов при переходе от пирита к другим сульфидным минералам [28], и её можно рассматривать не только как восстановительную систему для запуска реакций (7)-(11), но и катализатор для этих реакций.

Возрастание концентраций газов к поверхности, по-видимому, объясняется двумя причинами: вопервых, идет закономерное накопление поднимающихся снизу газов; во-вторых, в наиболее прогреваемом слое (20-30 см от поверхности) реакции газообразования идут более интенсивно, в том числе усиливается бактериальная активность; в-третьих, в поверхностном слое возможно усиление процессов газогенерации под действием УФ-излучения [32].

В геоэлектрической зональности вещества наиболее низкое удельное электрическое сопротивление (УЭС) обнаруживается в нижних горизонтах, распространяется до глубины зондирования 3 м и продолжается ниже (рис. 4).

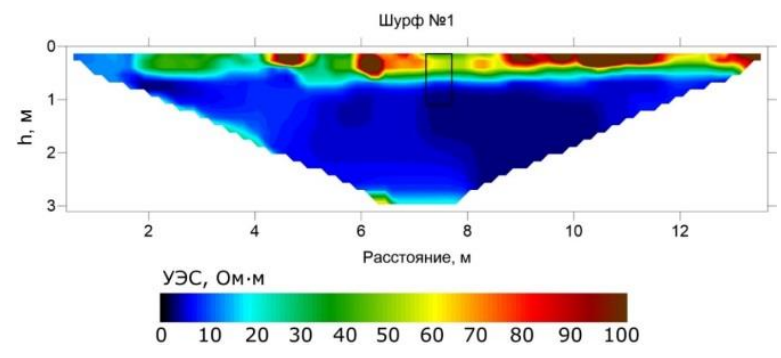

Рис. 4. Геоэлектрическая зональность вещества по линии ширфа № 1

Fig. 4. Geoelectric zoning of matter along the line of the pit no. 1

Это означает, что кислые растворы с высокими концентрациями растворенных форм элементов распространяются в грунтовые воды, где они могут мигрировать в разных направлениях в зависимости от гидрологического режима территории. Вместе с тем газовые аномалии в приземном слое воздуха определяются главным образом взаимодействиями в верхних частях разреза, но определенный вклад в их суммарную концентрацию вносят мигрирующие снизу газы. Основным фактором, влияющим на интенсивность газообразования, является температура среды, 
при повышении которой более интенсивно идут неорганические реакции и функционируют бактериальные сообщества - продуценты обсуждаемых газов.

На втором разрезе (шурф № 4) выявилось ещё более контрастное проявление процессов перераспределения вещества и кислотообразования. В верхних слоях разреза, представленных мелкозернистым веществом отходов, значения $\mathrm{pH}$ паст и водных вытяжек находились в нейтральной-слабощелочной области, но резко снизились в нижележащих горизонтах с увеличением электропроводности (т. е. минерализации межпоровых растворов), как показано на рис. 5.

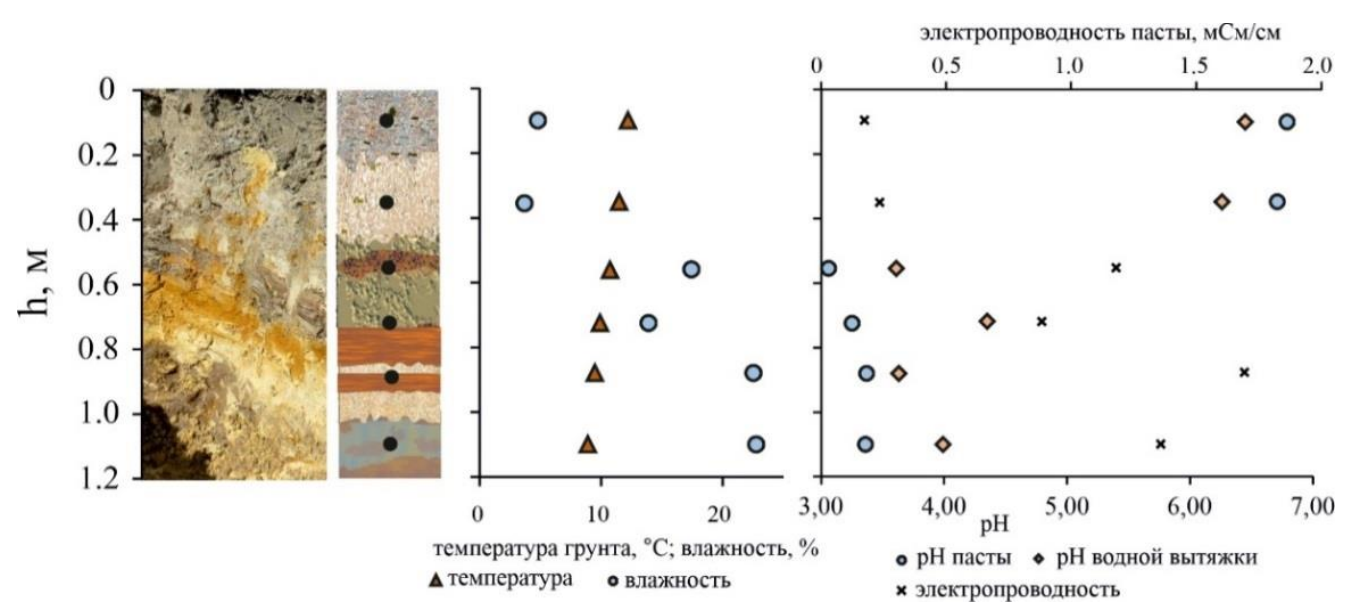

Рис. 5. Изменение параметров вещуества хвостохранилищз с глубиной (щурф № 4)

Fig. 5. Changes in the parameters of the tailing dump matter with depth (pit no. 4)

Распределение металлов по разрезу в твердом веществе незакономерно и, очевидно, зависит от первичной неоднородности вещества при складировании отходов (рис. 6). Однако так же, как разрезе шурфа № 1, накопление подвижных форм элементов увеличивается книзу. Распределение мышьяка по данным анализа водных вытяжек также отличается от распределения металлов, что определяется различием продуктов реакций при окислении сульфидов (1)-(4).

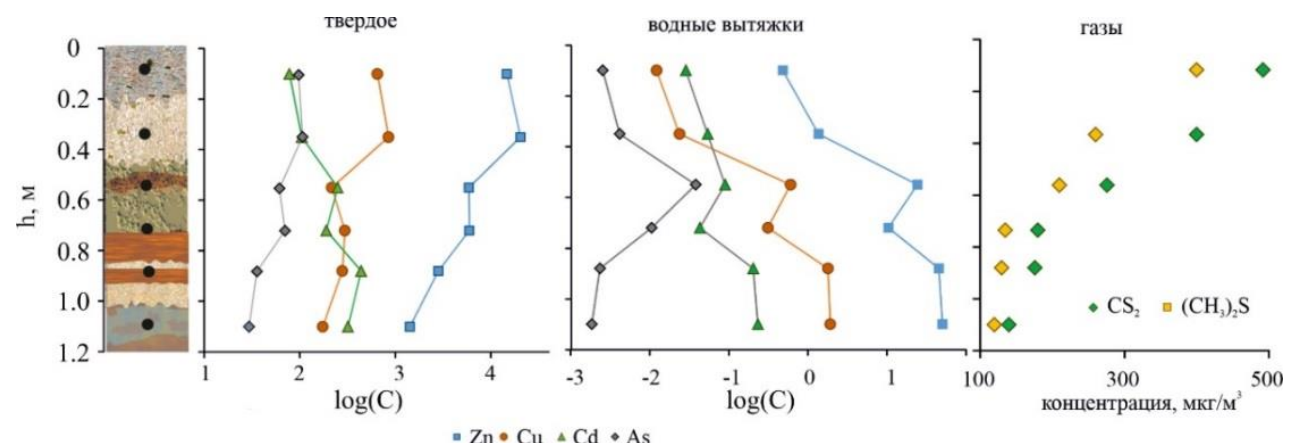

Рис. 6. Распределение общих концентраций металлов, их подвижных форм и некоторых газов по вертикали (иурф № 4). Примечание: $\log (C)$ - десятичный логарифм содержания элемента, выраженного в мг/л и в г/m в воде и в твердом веществе, соответственно

Fig. 6. Vertical distribution of total concentrations of metals, their mobile forms and some gases (pit no. 4). Note: $\log (C)$ is the decimal logarithm of the element content, expressed in $\mathrm{mg} / \mathrm{l}$ and $\mathrm{g} / \mathrm{t}$ in water and solid, respectively

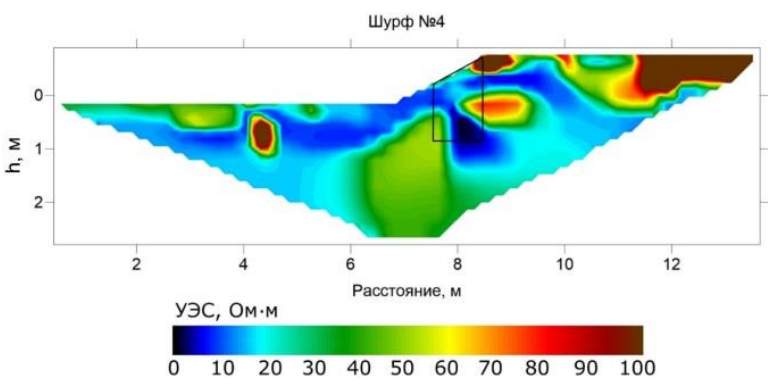

Рис. 7. Геоэлектрическая зональность вещества по линии шурфа № 4

Fig. 7. Geoelectric zoning of matter along the line of the pit no. 4
Геоэлектрическая зональность этого разреза полностью согласуется с изменением геохимических параметров вещества. Верхняя часть профиля представлена горизонтами с высоким УЭС (рис. 7), это слои с нейтральной средой и низкой минерализацией поровых растворов (рис. 5). Затем, при переходе в кислую область, УЭС разреза резко снижается и в забое шурфа становится близким к 1 (рис. 7).

При этом генерация газов, продуцируемых как неорганическими реакциями (сероуглерода), так и формирующихся при участии бактерий (диметилсульфида), наиболее высока в верхних слоях с нейтральной реакцией среды и высокими УЭС. Отметим, что в 
данном разрезе в нейтральных горизонтах (рН паст $6,7)$ концентрация $\mathrm{CS}_{2}$ в несколько раз выше, чем в верхних слоях шурфа № 1, представленных веществом с кислой средой (рН паст 2,4).

В результате активных взаимодействий в веществе отходов и перехода химических элементов в подвижные формы, а также концентрирования за счет испарения воды, водоёмы, сформированные на поверхности отходов, содержат высокие количества многих компонентов. Вода реки характеризуется существен- но более низкими концентрациями элементов по сравнению с водоёмами, но многие из них превышают фоновые значения в 3-8 раз $\left(\mathrm{SO}_{4}{ }^{2-}, \mathrm{Ca}, \mathrm{Cr}, \mathrm{Mn}, \mathrm{Zn}\right.$, $\mathrm{Pb}, \mathrm{Sr})$, а в некоторых точках концентрации элементов превышают предельно допустимые концентрации вредных веществ в водах водных объектов рыбохозяйственного значения (ПДК водоёмах; $\mathrm{Al}, \mathrm{Mn}, \mathrm{Fe}, \mathrm{Zn}, \mathrm{Pb}$ - на всем опробованном интервале реки (таблица). На рис. 8 приведены аномалии некоторых из обсуждаемых компонентов.

Таблица. Состав воды реки Малая Талмовая, водоёмов на поверхности хвостохранилища в сравнении с фоновыми кониентрациями для рек Западной Сибири, электропроводность УЭП в мкСм/см $\mathrm{HCO}_{3}^{-}-\mathrm{Cu}$ в мг/л, $\mathrm{Pb}-U$ в $\mu г / л$

Table. Water composition of the Malaya Talmovaya River, water bodies on the tailings surface in comparison with background concentrations for the rivers of Western Siberia, electrical conductivity EC in $\mu \mathrm{S} / \mathrm{cm} \mathrm{HCO}_{3}{ }^{-} \mathrm{Cu}$ in $m g / l, P b-U$ in $\mu g / l$

\begin{tabular}{|c|c|c|c|c|c|c|c|c|c|c|}
\hline \multirow{3}{*}{$\begin{array}{c}\text { Элементы } \\
\text { Elements } \\
\mathrm{pH} \\
\end{array}$} & \multicolumn{4}{|c|}{$\begin{array}{c}\text { Вода р. М. Талмовая } \\
\text { Water of the Malaya Talmovaya River }\end{array}$} & \multicolumn{3}{|c|}{$\begin{array}{c}\text { Водоёмы на хвостохранилище } \\
\text { Water bodies on the tailings surface }\end{array}$} & \multirow{2}{*}{\multicolumn{2}{|c|}{\begin{tabular}{|c|}
$\begin{array}{c}\text { Фон для рек Западной Сибири } \\
\text { Background for the rivers } \\
\text { of Western Siberia }\end{array}$ \\
{$[34,35]$}
\end{tabular}}} & \multirow{3}{*}{$\begin{array}{c}\text { ПДК } \\
\text { МАС [33] }\end{array}$} \\
\hline & \multirow{2}{*}{$\begin{array}{c}\begin{array}{c}\text { мин } \\
\min \end{array} \\
7,15 \\
\end{array}$} & \multirow{2}{*}{$\begin{array}{c}\begin{array}{c}\text { макс } \\
\max \end{array} \\
8,53 \\
\end{array}$} & \multirow{2}{*}{$\begin{array}{c}\text { среднее } \\
\text { mean }\end{array}$} & \multirow{2}{*}{$\begin{array}{l}\text { ст. откл } \\
\text { st. dev. } \\
0,40\end{array}$} & \multirow{2}{*}{$\frac{\mathrm{MT}-3 / 20}{3,46}$} & \multirow{2}{*}{ MT-5/20 } & \multirow{2}{*}{$\frac{\mathrm{MT}-5^{\prime} / 20}{7,13}$} & & & \\
\hline & & & & & & & & 7,64 & 7,6 & \\
\hline УЭП/ЕС & 182,3 & 291 & 212 & 34 & 3780 & 1214 & 922 & нд/nd & нд/nd & \\
\hline $\mathrm{HCO}_{3}^{-}$ & 210 & 260 & 236 & 13 & H.o./bdl & 250 & 190 & 360 & 126 & \\
\hline $\mathrm{SO}_{4}{ }^{2-}$ & 54 & 60 & 57 & 1,9 & 2500 & 990 & 700 & 3,6 & 15 & 100 \\
\hline $\mathrm{Cl}^{-}$ & 5,1 & 6,0 & 5,3 & 0,27 & 1,6 & 2,04 & 2,8 & 3,3 & 6,3 & 300 \\
\hline $\mathrm{NO}_{3}^{-}$ & 5,6 & 7,0 & 6,3 & 0,38 & $<0,5$ & $<0,5$ & $<0,5$ & 0,4 & 2,4 & 40 \\
\hline $\mathrm{PO}_{4}{ }^{3-}$ & 0,0088 & 0,077 & 0,044 & 0,020 & 1,9 & 0,076 & 0,11 & нд/nd & 0,20 & 0,05 \\
\hline $\mathrm{Br}^{-}$ & 0,042 & 0,065 & 0,054 & 0,0085 & 0,037 & 0,070 & 0,073 & 0,036 & нд/nd & 1,35 \\
\hline $\mathrm{I}^{-}$ & 0,015 & 0,023 & 0,018 & 0,0026 & 0,0010 & 0,029 & 0,013 & нд/nd & нд/nd & 0,4 \\
\hline $\mathrm{HCOO}^{-}$ & 0,30 & 0,44 & 0,37 & 0,05 & $<0,1$ & 0,4 & 0,6 & нд/nd & нд/nd & нд/nd \\
\hline $\mathrm{CH}_{3} \mathrm{COO}^{-}$ & 0,80 & 1,6 & 1,3 & 0,25 & $<0,5$ & $<0,5$ & $<0,5$ & нд/nd & нд/nd & нд/nd \\
\hline $\mathrm{NH}_{4}^{+}$ & 0,41 & 0,52 & 0,47 & 0,032 & 1,5 & 1,3 & 1,6 & 0,53 & нд/nd & 0,5 \\
\hline $\mathrm{Ca}^{2+}$ & 84 & 95 & 88 & 4,0 & 460 & 500 & 305 & 89 & 32 & 180 \\
\hline $\mathrm{Mg}^{2+}$ & 8,9 & 9,7 & 9,2 & 0,28 & 200 & 55 & 36 & 14 & 6,9 & 40 \\
\hline $\mathrm{Na}^{+}$ & 8,7 & 9,8 & 9,2 & 0,36 & 8,3 & 14 & 12 & 11 & 10 & 120 \\
\hline $\mathrm{K}^{+}$ & 1,1 & 1,7 & 1,3 & 0,18 & 5,6 & 1,9 & 2,8 & 1,4 & 1,6 & 50 \\
\hline $\mathrm{Si}$ & 3,4 & 3,7 & 3,5 & 0,11 & 32 & 4,4 & 2,3 & 4,8 & 2,5 & нд/nd \\
\hline $\mathrm{Fe}$ & 0,20 & 0,3 & 0,24 & 0,030 & 794 & 1,3 & 0,85 & 5,3 & 1,0 & 0,1 \\
\hline $\mathrm{Mn}$ & 0,070 & 0,16 & 0,12 & 0,029 & 78 & 30 & 15 & нд/nd & 0,019 & 0,05 \\
\hline $\mathrm{Al}$ & 0,014 & 0,25 & 0,085 & 0,0811 & 67 & 0,13 & 0,23 & 0,083 & нд/nd & 0,04 \\
\hline $\mathrm{Ba}$ & 0,056 & 0,064 & 0,060 & 0,0023 & 0,005 & 0,011 & 0,014 & 0,036 & 0,047 & 0,74 \\
\hline $\mathrm{Sr}$ & 0,30 & 0,32 & 0,31 & 0,0060 & 0,33 & 0,63 & 0,50 & 0,15 & 0,19 & 0,4 \\
\hline $\mathrm{Zn}$ & 0,12 & 0,19 & 0,15 & 0,021 & 1180 & 21 & 64 & 0,012 & 0,030 & 0,01 \\
\hline $\mathrm{Cu}$ & 0,0046 & 0,0072 & 0,0054 & 0,0007 & 41 & 0,075 & 0,12 & 0,0008 & 0,0023 & 0,001 \\
\hline $\mathrm{Pb}$ & 4,1 & 6,4 & 5,4 & 0,72 & 290 & 110 & 44 & 0,7 & 0,8 & 6,0 \\
\hline $\mathrm{Cd}$ & 0,42 & 0,60 & 0,54 & 0,061 & 2300 & 60 & 198 & 0,12 & 0,24 & 5,0 \\
\hline $\mathrm{Cr}$ & 6,3 & 13 & 11 & 2,3 & 60 & 14 & 15 & 5,1 & 2,8 & 70 \\
\hline Co & 0,38 & 0,49 & 0,44 & 0,039 & 340 & 44 & 24 & 0,32 & 0,60 & 10 \\
\hline $\mathrm{Ni}$ & 0,63 & 1,1 & 0,92 & 0,14 & 827 & 30 & 51 & 1,4 & 1,0 & 10 \\
\hline As & 1,9 & 2,2 & 2,1 & 0,14 & 32 & 0,8 & 0,9 & 0,16 & нд/nd & 50 \\
\hline $\mathrm{Sb}$ & 0,50 & 0,65 & 0,57 & 0,053 & 0,34 & 0,59 & 1,0 & 0,07 & 0,4 & нд/nd \\
\hline $\mathrm{Se}$ & 0,17 & 0,70 & 0,43 & 0,21 & 34 & 1,8 & 4,2 & нд/nd & нд/nd & 2,0 \\
\hline Mo & 0,67 & 1,1 & 0,77 & 0,14 & 0,93 & 0,30 & 0,52 & нд/nd & нд/nd & 1,0 \\
\hline $\mathrm{V}$ & 0,38 & 0,52 & 0,44 & 0,045 & 6,3 & 0,030 & 0,037 & нд/nd & нд/nd & 1,0 \\
\hline $\mathrm{U}$ & 1,1 & 1,2 & 1,2 & 0,032 & 117 & 1,8 & 0,78 & 0,67 & 0,51 & нд/nd \\
\hline
\end{tabular}

Примечание/Note: нд - нет данных/nd - по data; н.о. - ниже предела обнаружения/bdl - below detection limit

Существенной разницы между концентрациями всех рассматриваемых веществ ( $\mathrm{Mn}, \mathrm{Cd}, \mathrm{Zn}, \mathrm{SO}_{4}{ }^{2-}$ ) в реке до взаимодействия с отходами и после этого нет (рис. 8). Возможно, это связано с установлением состояния, при котором незначительно поступление в водоток различных соединений из отходов, непосредственно взаимодействующих с водой.

Отметим, что превышение над ПДК в воде реки для $\mathrm{Al}$ и $\mathrm{Cu}$ практически в каждой точке, над фоновыми значениями - только в водоёмах. Но для этих элементов разработанные нормативы ПДК ниже, чем фоновые значения: по Al - 0,083 [34], ПДК ${ }_{\mathrm{px}}-0,04$ мг/л [33]; по Сu фон 0,0023 [35], ПДК - 0,001 мг/л [33]. Поэтому обсуждение аномалий этих элементов здесь не приводится. При этом существование водоёмов с концентрациями элементов, намного превышающими их фоновые значения и ПДК означает возможность поступления этих растворов с 
сезонными потоками в реку. Состав воды реки не является постоянным, изменение метеорологических условий может привести к существенному возраста- нию концентраций многих токсичных компонентов, которые накапливаются в водоёмах вследствие описанных выше процессов.
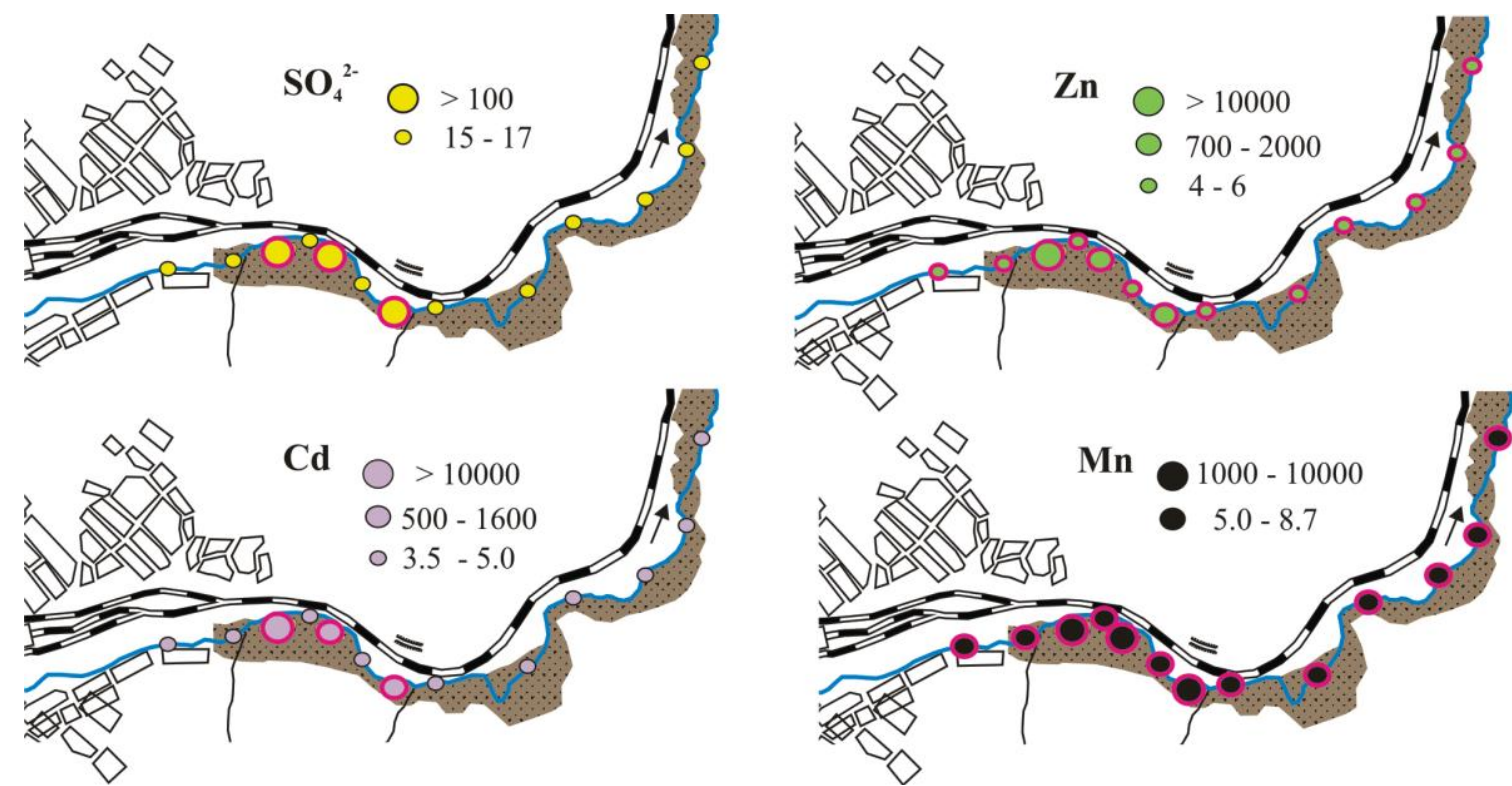

Рис. 8. Превымение концентраций некоторых элементов в воде р. М. Талмовой и в водоёмах на поверхности отходов над фоновыми значениями. Красным обведены точки, в которых содержание элемента превымает ПДК вредных веществ в водах водных объектов рыбохозяйственного значения

Fig. 8. Excess concentration of some elements in the water of the river. M. Talmova and in water bodies on the surface of waste above clarke values. The points at which the content of the element exceeds the MPC of harmful substances in the waters of water bodies of fishery significance are circled in red

\section{Заключение}

Обобщенная зональность техногенного тела на примере хвостохранилища Талмовские Пески может быть представлена следующим образом. В верхнем, прогреваемом, горизонте идёт интенсивное преобразование минеральной матрицы отходов и взаимодействие микробиоты с техногенным веществом, в результате которых накапливаются и формируются газы неорганического и биотического происхождения, в данном случае сероуглерод и диметилсульфид. Наиболее интенсивно газообразование идет в веществе с нейтральной средой. Окисление и разрушение вещества в верхних слоях приводят к переходу металлов в поровый раствор. Ниже по разрезу, с увеличением влажности температура снижается, возрастает кислотность, а биотические реакции становятся менее активными, но возрастает роль неорганических взаимодействий. Условия для процессов разрушения минеральной матрицы и накопления элементов в растворе тем стабильнее, чем глубже располо-

\section{СПИСОК ЛИТЕРАТУРЫ}

1. Salomons W. Environmental impact of metals derived from mining activities: processes, predictions, prevention // Journal of Geochemical exploration. - 1995. - V. 52. - № 1-2. - P. 5-23.

2. Akcil A., Koldas S. Acid Mine Drainage (AMD): causes, treatment and case studies // Journal of cleaner production. 2006. - V. 14. - № 12-13. - P. 1139-1145.

3. Lottermoser B.G. Mine wastes. Characterization, treatment, environmental impacts. 2nd ed. - Berlin, Heidelberg: SpringerVerlag, 2010. - $335 \mathrm{p}$

4. Hudson-Edwards K.A., Jamieson H.E., Lottermoser B.G. Mine wastes: past, present, future // Elements. - 2011. - V. 7. - № 6. - P. 375-380. жен горизонт, что следует из распределения валовых и растворённых форм элементов. К растворам, формирующимся in situ в глубоких горизонтах, добавляются растворы, фильтрующиеся сверху. Если образующиеся газы уходят по межпоровым путям кверху, то металлы с растворами концентрируются внизу.

В результате в р. Малая Талмовая, протекающей в непосредственной близости от хвостохранилища, и в водоёмах на поверхности отходов сформированы контрастные гидрохимические аномалии по многим компонентам: сульфат-ионам и металлам, концентрации которых достигают высоких значений (мг/л): $\mathrm{SO}_{4}{ }^{2-}-2500 ; \mathrm{Zn}-1200 ; \mathrm{Mn}-78 ; \mathrm{Cd}-2,3$. Наличие водоёмов с высокоминерализованными растворами может приводить к залповым выносам токсикантов в реку в дождливое время или в период снеготаяния.

Работа выполнена при финансовой поддержке РНФ (грант № 19-17-00134).

5. Skousen J.G., Ziemkiewicz P.F., McDonald L.M. Acid mine drainage formation, control and treatment: Approaches and strategies // The Extractive Industries and Society. - 2019. V. 6. - № 1. - P. 241-249.

6. Ofori-Sarpong G., Amankwah R. Potential of mine waste rock to generate acid mine drainage - a case study in south-western Ghana // New Frontiers in Natural Resources Management in Africa. Cham: Springer, 2019. - P. 79-91.

7. Chandra A.P., Gerson A.R. The mechanisms of pyrite oxidation and leaching: a fundamental perspective // Surface Science Reports. - 2010. - V. 65. - № 9. - P. 293-315.

8. Corkhill C.L., Vaughan D.J. Arsenopyrite oxidation - a review // Applied Geochemistry. - 2009. - V. 24. - № 12. - P. 2342-2361. 
9. Heavy metal distribution and chemical speciation in tailings and soils around a $\mathrm{Pb}-\mathrm{Zn}$ mine in Spain / L. Rodríguez, E. Ruiz, J. Alonso-Azcárate, J. Rincón // Journal of Environmental Management. - 2009. - V. 90. - № 2. - P. 1106-1116.

10. Ecological and health risks of heavy metal on farmland soils of mining areas around Tongling City, Anhui, China / Z. Shen, D. Xu, L. Li, J. Wang, X. Shi // Environmental Science and Pollution Research. - 2019. - V. 26. - № 15. - P. 15698-15709.

11. Gyamfi E., Appiah-Adjei E.K., Adjei K.A. Potential heavy metal pollution of soil and water resources from artisanal mining in Kokoteasua, Ghana // Groundwater for Sustainable Development. - 2019. - V. 8. - P. 450-456.

12. Minnaar A. Water pollution and contamination from gold mines: acid mine drainage in Gauteng Province, South Africa // Water, Governance, and Crime Issues. - Cham: Springer, 2020. - P. 193-219.

13. Nordstrom D.K. Hydrogeochemical processes governing the origin, transport and fate of major and trace elements from mine wastes and mineralized rock to surface waters // Applied Geochemistry. - 2011. - V. 26. - № 11. - P. 1777-1791

14. Characterization of a gold extraction plant environment in assessing the hazardous nature of accumulated wastes (Kemerovo region, Russia) / S. Bortnikova, V. Olenchenko, O. Gaskova, N. Yurkevich, N. Abrosimova, E. Shevko, A. Edelev, T. Korneeva, I. Provornaya, L. Eder // Applied Geochemistry. - 2018. - V. 93. - P. 145-157.

15. Mechanisms of low-temperature vapor-gas streams formation from sulfide mine waste / S. Bortnikova, N. Yurkevich, A. Devyatova, O. Saeva, O. Shuvaeva, A. Makas, M. Troshkov, N. Abrosimova, M. Kirillov, T. Korneeva, T. Kremleva, N. Fefilov, G. Shigabaeva // Science of the Total Environment. - 2019. - V. 647. - P. 411-419.

16. Assessment of emissions of trace elements and sulfur gases from sulfide tailings / S.B. Bortnikova, N.V. Yurkevich, N.A. Abrosimova, A.Y. Devyatova, A.V. Edelev, A.L. Makas, M.L. Troshkov // Journal of Geochemical Exploration. - 2018. - V. 186. - P. 256-269.

17. Sulfur and nitrogen gases in the vapor streams from ore cyanidation wastes at a sharply continental climate, Western Siberia, Russia / N. Yurkevich, S. Bortnikova, N. Abrosimova, A. Makas, V. Olenchenko, Nik. Yurkevich, A. Edelev, O. Saeva, A. Shevko // Water, Air, and Soil Pollution. - 2019. - V. 230. - № 12. - 307 p.

18. The combination of geoelectrical measurements and hydrogeochemical studies for the evaluation of groundwater pollution in mining tailings areas / S. Bortnikova, N. Yurkevich, E. Bessonova, Y. Karin, O. Saeva // Threats to the Quality of Groundwater Resources. The Handbook of Environmental Chemistry. - Berlin, Heidelberg: Springer, 2013. - V 40. - P. 239-256.

19. Лабазин Г.С. Структурно-морфологические особенности полиметаллических месторождений Салаирских рудников и геологические условия их нахождения // Цветные металлы. 1940. - № 3. - C. 14-20.

20. Зеркалов В.И. Минералогия и геология колчеданных медносвинцово-цинковых месторождений северо-восточного $\mathrm{Ca}$ лаира: автореф. дис. ... канд. геол.-минерал. наук. - Томск, 1962. $-20 \mathrm{c}$

21. Поспелов Г.Л., Лапухов А.С. Строение и развитие рудообразующих флюидных динамических систем с полиморфной зональностью (на примере Салаирского рудного поля) // Физи- ческие и физико-химические процессы в динамических рудообразующих системах. - Новосибирск: Наука, 1971. - С. 8-55.

22. Лапухов А.С. Зональность колчелданно-полиметаллических месторождений. - Новосибирск: Наука, 1975. - 264 с.

23. Дистанов Э.Г. Колчеданно-полиметаллические месторождения Сибири. - Новосибирск: Наука, 1977. - 351 с.

24. Бортникова С.Б. Геолого-геохимические особенности золотого оруденения в полиметаллических полях северо-восточного Салаира: дис. .... канд. геол.-минерал. наук. - Новосибирск, 1989. $-206 \mathrm{c}$.

25. Бортникова С.Б., Гаськова О.Л., Бессонова Е.П. Геохимия техногенных систем. - Новосибирск: Изд-во СО РАН, филиал «ГЕО», 2006. $-170 \mathrm{c}$

26. Loke M.H. Electrical imaging surveys for environmental and engineering studies: a practical guide to 2-D and 3-D surveys. Austin: Advanced Geosciences Inc., 1999. - 61 p.

27. Sobek A.A. Field and laboratory methods applicable to overburdens and minesoils. - USA: Industrial Environmental Research Laboratory, Office of Research and Development, US Environmental Protection Agency, 1978. - 203 p.

28. Taylor C.H., Kesler S.E., Cloke P.L. Sulfur gases produced by the decomposition of sulfide minerals: Application to geochemical exploration // Journal of Geochemical Exploration. - 1982. - V. 17. - P. 165-185

29. Hinkle M.E., Lovell J.S. Sulphur gases // Handbook of Exploration Geochemistry. - Amsterdam: Elsevier Science BV, 2000. - V. 7. P. 249-289.

30. Heinen W., Lauwers A. M. Organic sulfur compounds resulting from the interaction of iron sulfide, hydrogen sulfide and carbon dioxide in an anaerobic aqueous environment // Origins of Life and Evolution of the Biosphere. - 1996. - V. 26. - № 2. - P. 131-150.

31. Rickard D., Luther G.W. Chemistry of iron sulfides // Chemical reviews. - 2007. - V. 107. - № 2. - P. 514-562.

32. Photochemical production of carbonyl sulfide, carbon disulfide and dimethyl sulfide in a lake water / Q. Du, Y. Mu, C. Zhang, J. Liu, Y. Zhang, C. Liu // Journal of Environmental Sciences. 2017. - V. 51. - P. 146-156.

33. Приказ Министерства сельского хозяйства Российской Федерации от 13.12.2016 г. № 552 (ред. от 10.03.2020) «Об утверждении нормативов качества воды водных объектов рыбохозяйственного значения, в том числе нормативов предельно допустимых концентраций вредных веществ в водах водных объектов рыбохозяйственного значения». // Официальный интернет-портал правовой информации. 2020. URL: http:/publication.pravo.gov.ru/Document/ View/0001202006160052/ (дата обращения 20.10.2020).

34. Колубаева Ю.В., Шварцев С.Л., Копылова Ю.Г. Геохимия вод северной части Колывань-Томской складчатой зоны // Известия высших учебных заведений. Геология и разведка. 2010. - № 2. - C. 50-58

35. Эколого-геохимическое состояние речных вод Средней Сибири / С.Л. Шварцев, О.Г. Савичев, Г.Г. Вертман, Р.Ф. Зарубина, Н.Г. Наливайко, Н.Г. Трифонова, Ю.П. Туров, Л.Ф. Фризен, В.В. Янковский // Водные ресурсы. - 1996. - Т. 23. - № 6. C. $723-731$

Поступила 09.12.2020 г.

\section{Информация об авторах}

Бортникова С.Б., доктор геолого-минералогических наук, профессор, заведующая лабораторией геоэлектрохимии Института нефтегазовой геологии и геофизики им. А.А. Трофимука СО РАН.

Юркевич Н.В., кандидат геолого-минералогических наук, ведущий научный сотрудник, лаборатория геоэлектрохимии Института нефтегазовой геологии и геофизики им. А.А. Трофимука СО РАН.

Eделев A.B., кандидат геолого-минералогических наук, старший научный сотрудник, лаборатория геоэлектрохимии Института нефтегазовой геологии и геофизики им. А.А. Трофимука СО РАН.

Саева О.П., кандидат геолого-минералогических наук, старший научный сотрудник, лаборатория геоэлектрохимии Института нефтегазовой геологии и геофизики им. А.А. Трофимука СО РАН.

Грахова С.П., научный сотрудник, лаборатория геоэлектрохимии Института нефтегазовой геологии и геофизики им. А.А. Трофимука СО РАН.

Волынкин C.C., младший научный сотрудник, лаборатория геоэлектрохимии Института нефтегазовой геологии и геофизики им. А.А. Трофимука СО РАН.

Карин Ю.Г., научный сотрудник, лаборатория геоэлектрохимии Института нефтегазовой геологии и геофизики им. А.А. Трофимука СО РАН. 
UDC 550.837.312:556.531.4

\section{HYDROCHEMICAL AND GASEOUS ANOMALIES ON SULFIDE TAILINGS (SALAIR, KEMEROVO REGION)}

Svetlana B. Bortnikova ${ }^{1}$,
BortnikovaSB@ipgg.sbras.ru

Nataliya V. Yurkevich ${ }^{1}$, YurkevichNV@ipgg.sbras.ru

Aleksey V. Edelev 1 , EdelevAV@ipgg.sbras.ru

Olga P. Saeva ${ }^{1}$ SaevaOP@ipgg.sbras.ru

1 Trofimuk Institute of Petroleum Geology and Geophysics SB RAS,

3, Koptyug avenue, Novosibirsk, 630090, Russia.
Sofiya P. Grakhova ${ }^{1}$, GrakhovaSP@ipgg.sbras.ru

Sergey S. Volynkin 1 , VolynkinSS@ipgg.sbras.ru

Yuriy G. Karin ${ }^{1}$, KarinYG@ipgg.sbras.ru

The relevance of the research consists in obtaining data on the processes occurring in the sulfide mine waste, their transformation under the influence of oxidative factors, migration of toxic components into the environment.

The main aim of the research is to determine the vertical zoning by elemental composition and content of gases (carbon disulfide and dimethyl sulfide) in the tailings, as well as to establish the hydrochemical anomalies in the nearest river as a result of migration of potentially toxic elements with water flows from the tailings.

Object of the research is the abandoned tailings dump of the Salair mining and processing plant - Talmovskie Peski (Salair, Kemerovo region), containing wastes of cyanidation and flotation of barite-polymetallic ores.

Methods. In the field, thermometry, gas analysis, electric exploration by the resistance method in the electrotomography mode were carried out. Solid and liquid sampling was carried out in accordance with generally accepted techniques. The laboratory study of the chemical composition was carried out by the methods of conductometry, potentiometry, capillary electrophoresis, and mass spectrometry with inductively coupled plasma.

Results. The vertical distribution of the total element concentrations is determined by the heterogeneity of the stored tailings material. Using the example of two cross sections to a depth of $1,2 \mathrm{~m}$, it was determined that the humidity of the substance increases with depth, and the temperature, $\mathrm{pH}$ pastes and aqueous extracts decrease. With depth, the amount of water-soluble species of metals increases due to the transformation of sulfides in acidic conditions, as well as due to the inflow from the upper horizons. The gas generation of carbon disulfide and dimethyl sulfide increases towards the upper layers of the tailings, which is due to the both transformation of minerals, and active functioning of biota in the upper heated layers with a neutral reaction of the medium. As a result of active tailings-water-gas interactions, contrasting hydrochemical anomalies with high metal concentrations are formed in the Malaya Talmovaya River, in the channel of which the tailing dump is located.

\section{Key words:}

Tailings, emission of gases, micro-electrical tomography, sulfur gases, natural water pollution, electrical resistivity, acidic waters.

This work was supported by the Russian Science Foundation [19-17-00134].

\section{REFERENCES}

1. Salomons W. Environmental impact of metals derived from mining activities: processes, predictions, prevention. Journal of Geochemical exploration, 1995, vol. 52, no. 1-2, pp. 5-23.

2. Akcil A., Koldas S. Acid Mine Drainage (AMD): causes, treatment and case studies. Journal of cleaner production, 2006, vol. 14 , no. 12-13, pp. 1139-1145.

3. Lottermoser B.G. Mine Wastes. Characterization, Treatment, Environmental Impacts. $2^{\text {nd }}$ ed. Berlin, Heidelberg, Springer-Verlag, 2010. 335 p.

4. Hudson-Edwards K.A., Jamieson H.E., Lottermoser B.G. Mine wastes: past, present, future. Elements, 2011, vol. 7, no. 6, pp. 375-380.

5. Skousen J.G., Ziemkiewicz P.F., McDonald L.M. Acid mine drainage formation, control and treatment: Approaches and strategies. The Extractive Industries and Society, 2019, vol. 6, no. 1, pp. 241-249.

6. Ofori-Sarpong G., Amankwah R. Potential of mine waste rock to generate acid mine drainage-a case study in South-Western Ghana. New Frontiers in Natural Resources Management in Africa. Cham, Springer, 2019. pp. 79-91.

7. Chandra A.P., Gerson A.R. The mechanisms of pyrite oxidation and leaching: a fundamental perspective. Surface Science Reports, 2010, vol. 65, no. 9, pp. 293-315.
8. Corkhill C.L., Vaughan D.J. Arsenopyrite oxidation - a review. Applied Geochemistry, 2009, vol. 24, no. 12, pp. 2342-2361.

9. Rodríguez L., Ruiz E., Alonso-Azcárate J., Rincón J. Heavy metal distribution and chemical speciation in tailings and soils around a $\mathrm{Pb}-\mathrm{Zn}$ mine in Spain. Journal of Environmental Management, 2009, vol. 90, no. 2, pp. 1106-1116.

10. Shen Z., Xu D., Li L., Wang J., Shi X. Ecological and health risks of heavy metal on farmland soils of mining areas around Tongling City, Anhui, China. Environmental Science and Pollution Research, 2019, vol. 26, no. 15, pp. 15698-15709.

11. Gyamfi E., Appiah-Adjei E.K., Adjei K.A. Potential heavy metal pollution of soil and water resources from artisanal mining in Kokoteasua, Ghana. Groundwater for Sustainable Development, 2019, vol. 8, pp. $450-456$.

12. Minnaar A. Water pollution and contamination from gold mines: acid mine drainage in Gauteng Province, South Africa. Water, Governance, and Crime Issues. Cham, Springer, 2020. pp. 193-219.

13. Nordstrom D.K. Hydrogeochemical processes governing the origin, transport and fate of major and trace elements from mine wastes and mineralized rock to surface waters. Applied Geochemistry, 2011, vol. 26, no. 11, pp. 1777-1791.

14. Bortnikova S., Olenchenko V., Gaskova O., Yurkevich N., Abrosimova N., Shevko E., Edelev A., Korneeva T., Provornaya I., 
Eder L. Characterization of a gold extraction plant environment in assessing the hazardous nature of accumulated wastes (Kemerovo region, Russia). Applied Geochemistry, 2018, vol. 93, pp. 145-157.

15. Bortnikova S., Yurkevich N., Devyatova A., Saeva O., Shuvaeva O., Makas A., Troshkov M., Abrosimova N., Kirillov M., Korneeva T., Kremleva T., Fefilov N., Shigabaeva G. Mechanisms of low-temperature vapor-gas streams formation from sulfide mine waste. Science of the Total Environment, 2019, vol. 647, pp. 411-419.

16. Bortnikova S.B., Yurkevich N.V., Abrosimova N.A., Devyatova A.Y., Edelev A.V., Makas A.L., Troshkov M.L. Assessment of emissions of trace elements and sulfur gases from sulfide tailings. Journal of Geochemical Exploration, 2018, vol. 186, pp. 256-269.

17. Yurkevich N., Bortnikova S., Abrosimova N., Makas A., Olenchenko V., Yurkevich Nik., Edelev A., Saeva O., Shevko A. Sulfur and nitrogen gases in the vapor streams from ore cyanidation wastes at a sharply continental climate, Western Siberia, Russia. Water, Air, and Soil Pollution, 2019, vol. 230, Iss. 12, 307.

18. Bortnikova S., Yurkevich N., Bessonova E., Karin Y., Saeva O. The combination of geoelectrical measurements and hydrogeochemical studies for the evaluation of groundwater pollution in mining tailings areas. Threats to the Quality of Groundwater Resources. The Handbook of Environmental Chemistry. Berlin, Heidelberg, Springer, 2013. Vol. 40, pp. 239-256.

19. Labazin G.S. Strukturno-morfologicheskie osobennosti polimetallicheskikh mestorozhdeniy Salairskikh rudnikov i geologicheskie usloviya ikh nakhozhdeniya [Structural and morphological features of polymetallic deposits of the Salair mines and the geological conditions of their location]. Cvetnye metally, 1940, no. 3, pp. 14-20.

20. Zerkalov V.I. Mineralogiva i geologiva kolchedannykh mednosvintsovo-tsinkovykh mestorozhdeniy severo-vostochnogo Salaira. Avtoreferat Dis. Kand. nauk [Mineralogy and geology of pyrite copper-lead-zinc deposits of northeastern Salair. Cand. Diss. Abstract]. Tomsk, $1962.20 \mathrm{p}$.

21. Pospelov G.L., Lapukhov A.S. Stroenie i razvitie rudoobrazuyushchikh flyuidnykh dinamicheskikh sistem s polimorfnoy zonalnostyu (na primere Salairskogo rudnogo polya) [The structure and development of ore-forming fluid dynamic systems with polymorphic zoning (on the example of the Salair ore field)]. Fizicheskie i fiziko-khimicheskie protsessy $v$ dinamicheskikh rudoobrazuyushchikh sistemakh [Physical and physicochemical processes in dynamic ore-forming systems]. Novosibirsk, Nauka Publ., 1971. pp. 8-55.

22. Lapukhov A.S. Zonalnost kolcheldanno-polimetallicheskikh mestorozhdeniy [Zoning of colcheldno-polymetallic deposits]. Novosibirsk, Nauka Publ., 1975. 264 p.

23. Distanov E.G. Kolchedanno-polimetallicheskie mestorozhdeniya Sibiri [Pyrite-polymetallic deposits of Siberia]. Novosibirsk, Nauka Publ., 1977. 351 p.

24. Bortnikova S.B. Geologo-geokhimicheskie osobennosti zolotogo orudeneniya $v$ polimetallicheskikh polyakh severo-vostochnogo Salaira. Dis. Kand. nauk [Geological and geochemical features of gold mineralization in polymetallic fields of northeastern Salair. Cand. Diss.]. Novosibirsk, 1989. 20 p.

25. Bortnikova S.B., Gaskova O.L., Bessonova E.P. Geokhimiya tekhnogennykh sistem [Geochemistry of technogenic systems]. Novosibirsk, SO RAN Publ., branch «GEO», 2006. 170 p.

26. Loke M.H. Electrical imaging surveys for environmental and engineering studies: a practical guide to 2-D and 3-D surveys. Austin, Advanced Geosciences Inc., 1999. 61 p.

27. Sobek A.A. Field and laboratory methods applicable to overburdens and minesoils. USA, Industrial Environmental Research Laboratory, Office of Research and Development, US Environmental Protection Agency, 1978. 203 p.

28. Taylor C.H., Kesler S.E., Cloke P.L. Sulfur gases produced by the decomposition of sulfide minerals: Application to geochemical exploration. Journal of Geochemical Exploration, 1982, vol. 17, pp. $165-185$.

29. Hinkle M.E., Lovell J.S. Sulphur gases. Handbook of Exploration Geochemistry. Vol. 7. Amsterdam, Elsevier Science BV, 2000. pp. 249-289.

30. Heinen W., Lauwers A. M. Organic sulfur compounds resulting from the interaction of iron sulfide, hydrogen sulfide and carbon dioxide in an anaerobic aqueous environment. Origins of Life and Evolution of the Biosphere, 1996, vol. 26, no. 2, pp. 131-150.

31. Rickard D., Luther G.W. Chemistry of iron sulfides. Chemical reviews, 2007, vol. 107, no. 2, pp. 514-562.

32. Du Q., Mu Y., Zhang C., Liu J., Zhang Y., Liu C. Photochemical production of carbonyl sulfide, carbon disulfide and dimethyl sulfide in a lake water. Journal of Environmental Sciences, 2017, vol. 51, pp. 146-156.

33. Prikaz Ministerstva selskogo khozyaystva Rossiyskoy Federatsii ot 13.12.2016 g. № 552 (red. ot 10.03.2020) «Ob utverzhdenii normativov kachestva vody vodnykh obektov rybokhozyaystvennogo znacheniya, $v$ tom chisle normativov predelno dopustimykh kontsentratsy vrednykh veshchestv $v$ vodakh vodnykh obektov rybokhozyaystvennogo znacheniya» [Order of the Ministry of Agriculture of the Russian Federation of 13.12.2016 no. 552 (revised from 10.03.2020) «On approval of water quality standards for water bodies of fishery significance, including standards for maximum permissible concentrations of harmful substances in the waters of water bodies of fishery significance»]. 2020. Available at: http://publication.pravo.gov.ru/Document/View/0001202006160052/ (accessed 20 October 2020).

34. Kolubaeva Yu.V., Shvartsev S.L., Kopylova Yu.G. Water geochemistry of the north of Kolyvan-Tomsk folded zone. Proceedings of Higher Educational Establishments: Geology and Exploration, 2010, no. 2, pp. 50-58. In Rus.

35. Shvartsev S.L., Savichev O.G., Vertman G.G., Zarubina R.F., Nalivaiko N.G., Trifonova N.G., Turov Yu.P., Frizen L.F., Yankovsky V.V. Ecological and geochemical state of river waters in Central Siberia. Water resources, 1996, vol. 23, no. 6, pp. 673-682.

Received: 9 December 2020.

\section{Information about the authors}

Svetlana B. Bortnikova, Dr.Sc., professor, head of the department, Trofimuk Institute of Petroleum Geology and Geophysics of Siberian Branch Russian Academy of Sciences.

Nataliya V. Yurkevich, Cand. Sc., leading researcher, Trofimuk Institute of Petroleum Geology and Geophysics of Siberian Branch Russian Academy of Sciences.

Aleksey V. Edelev, Cand. Sc., senior researcher, Trofimuk Institute of Petroleum Geology and Geophysics of Siberian Branch Russian Academy of Sciences.

Olga P. Saeva, Cand. Sc., senior researcher, Trofimuk Institute of Petroleum Geology and Geophysics of Siberian Branch Russian Academy of Sciences.

Sofiya P. Grakhova, research associate, Trofimuk Institute of Petroleum Geology and Geophysics of Siberian Branch Russian Academy of Sciences.

Sergey S. Volynkin, junior researcher, Trofimuk Institute of Petroleum Geology and Geophysics of Siberian Branch Russian Academy of Sciences.

Yuriy G. Karin, research associate, Trofimuk Institute of Petroleum Geology and Geophysics of Siberian Branch Russian Academy of Sciences. 